ORIGINAL ARTICLE

\title{
Establishment of a protocol to test fatigue of the trunk muscles
}

\author{
G Corin, P H Strutton, A H McGregor
}

Br J Sports Med 2005;39:731-735. doi: 10.1136/bjsm.2004.015537

See end of article for authors' affiliations ......................

Correspondence to: Dr McGregor, 7th Floor, East Wing, Charing Cross Hospital, Fulham Palace Road, Hammersmith, London W6 8RF, UK; a mcgregor@imperial.ac.uk

Accepted 17 March 2005

\begin{abstract}
Background: Muscle fatigue has high relevance in human performance yet little research has evaluated how it should be assessed.

Objective: To perform a pilot study to identify suitable methods of generating and assessing fatigue of the trunk flexor and extensor muscles.

Methods: Sixteen university rugby players (mean (SEM) age $21.9(0.2)$ years) were recruited and subjected to four protocols (A, B, C, D), separated by a week to allow recovery, with peak torque being recorded during each test: $A$, isokinetic measurements before and after fatigue, with a 10 repetition isokinetic fatigue period; $B$, isokinetic measurements before and after fatigue with a 45 second isometric fatigue period; $C$, isometric measurements before and after fatigue with a 10 repetition isokinetic fatigue period; $D$, isometric measurements before and after fatigue with a 45 second isometric fatigue period. All were conducted during flexion and extension of the trunk on the Cybex Norm Isokinetic Dynamometer trunk flexion-extension unit.

Results: All subjects completed all four protocols. Fatigue induction appeared more effective in flexion than extension. Significant differences in mean peak torque before and after fatigue were seen in protocols $A$, $B$, and $D$ in flexion and only in protocol $D$ for extension. In flexion, protocol D produced the greatest fatigue, peak torque being $16.2 \%$ less after than before fatigue, suggesting greatest sensitivity.

Conclusions: Protocol D, which incorporates isometric testing and fatigue protocols, appears to be able to produce fatigue most effectively, and therefore may provide the most valid assessment of fatigue in the trunk flexor and extensor muscles.
\end{abstract}

A $\mathrm{n}$ often applied definition of fatigue is an "exerciseinduced reduction in maximal voluntary muscle force" ${ }^{\prime 1}$ This should not be confused with the limit of endurance, which is the time period for which a constant (non-fatiguing) force output can be maintained. ${ }^{2}$ Further confusion can arise about whether this endurance is assessed maximally or submaximally, and as a result of test position.

Muscle fatigue is a complex and multifaceted process involving physiological, biomechanical, and psychological elements. ${ }^{4}$ It is an important phenomenon, as there are numerous proven relations with work related musculoskeletal injuries. ${ }^{45}$ Being able to identify and test muscle fatigue is of importance in understanding the ergonomics and physiology of work and sport induced injury. Improved working practices and sport techniques, training, and testing can then result. ${ }^{45}$

Many studies of muscle fatigue have actually assessed the limit of endurance (by measuring the ability to maintain a sustained contraction), as opposed to fatigue as defined above. ${ }^{4}$ Consequently, very few studies have evaluated the optimal method for assessing muscle fatigue. There are two fundamental ways to measure muscle strength and therefore fatigue: isometrically and isokinetically. Isometric measurement involves contraction against a fixed, immovable object (a static test), whereas isokinetic assessment is dynamic muscular contraction at a controlled velocity (repeated contractions ). ${ }^{7}$ However, it is not known which approach is optimal for firstly creating muscle fatigue and secondly quantifying it. Traditionally the Biering-Sorenson test has been used to assess fatigue of the trunk extensor muscle group. ${ }^{8}$ However, this test is not performed against maximal resistance as it is only performed against gravity. Therefore it may not be a true measure of fatigue because, according to the definition used above, ${ }^{1}$ it would not reflect a reduction in maximal voluntary muscle force and is therefore more a measure of endurance. It also may not permit a large range of performance skills to be assessed because an athlete may be capable of performing the test with ease whereas a patient with low back pain may struggle to resist gravity. It is also limited to assessment of the trunk extensor muscle group only.

The assessment of fatigue and endurance in the trunk is important because it has been widely reported that patients with low back pain develop a deconditioning syndrome that particularly influences the strength and function of the back muscles, ${ }^{9-16}$ with such patients being much weaker than healthy controls..$^{17-21}$ Lack of endurance has also been highlighted as a key factor for predicting low back pain, ${ }^{22}$ and this suggests that the assessment of fatigue warrants further investigation. Consequently, this study focused on the flexorextensor muscles of the spine, investigating different methods of testing and evaluating maximal fatigue of the trunk muscles.

\section{METHODS}

Study population

Ethical approval for this study was obtained from the Riverside Research Ethics Committee, at Charing Cross Hospital, London, UK. Sixteen male student rugby players (mean (SEM) age 21.9 (0.2) years, weight 91.2 (3.3) kg, height $1.8(0.03) \mathrm{m}$ ) were recruited from the college's rugby club, and written informed consent was obtained. All current members of the college club who were in full training and eligible for competition were eligible for inclusion in this study, although subjects with a current or recent low back injury (time off training or intervention four weeks before testing) were excluded from taking part. All testing fell midseason in the rugby calendar. 


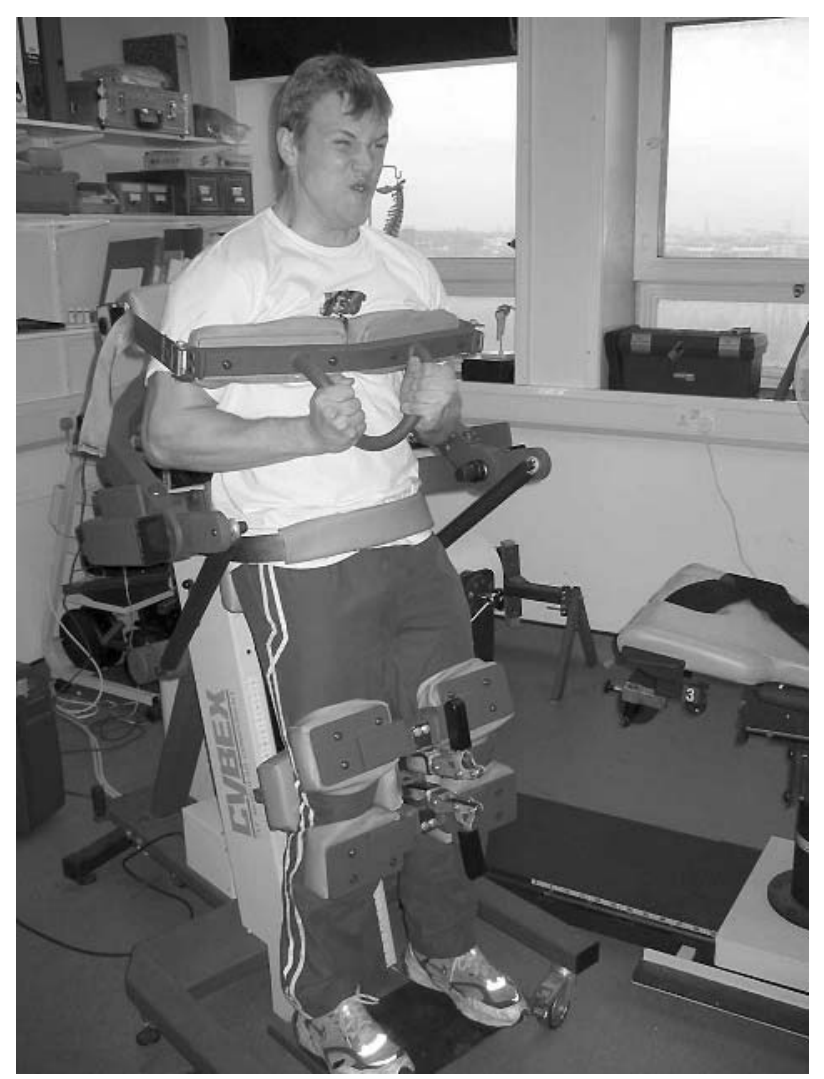

Figure 1 Experimental set up (with permission from subject).

\section{Study protocol}

Four trunk fatigue protocols were tested on four separate occasions, with an interval of one week between testing, all were allowed a period of familiarisation with the equipment. The volunteers received no specific training for trunk muscle exercise before or during the study.

\section{Test protocol}

Tests were carried out using the Cybex Norm Isokinetic Dynamometer (Henley Healthcare, Sugarland, Texas, USA) with an incorporated trunk flexion/extension unit (fig 1). The lower limbs were stabilised by tibial and thigh pads. A belt secured the pelvis to limit the use of the hip flexors. A shoulder harness and backrest provided anchorage to the moving upper section of the apparatus. Range of motion was recorded from $-10^{\circ}$ of hyperextension to $80^{\circ}$ flexion as recorded through the Cybex system, which represented the limits of range of the system rather than the ranges of the subjects. All isokinetic testing was performed through this range. Subjects were tested according to the following four protocols in sequential order. These protocols were derived from previous experience obtained testing elite rowers, ${ }^{23}$ but further research is required to investigate duration and repetition number.
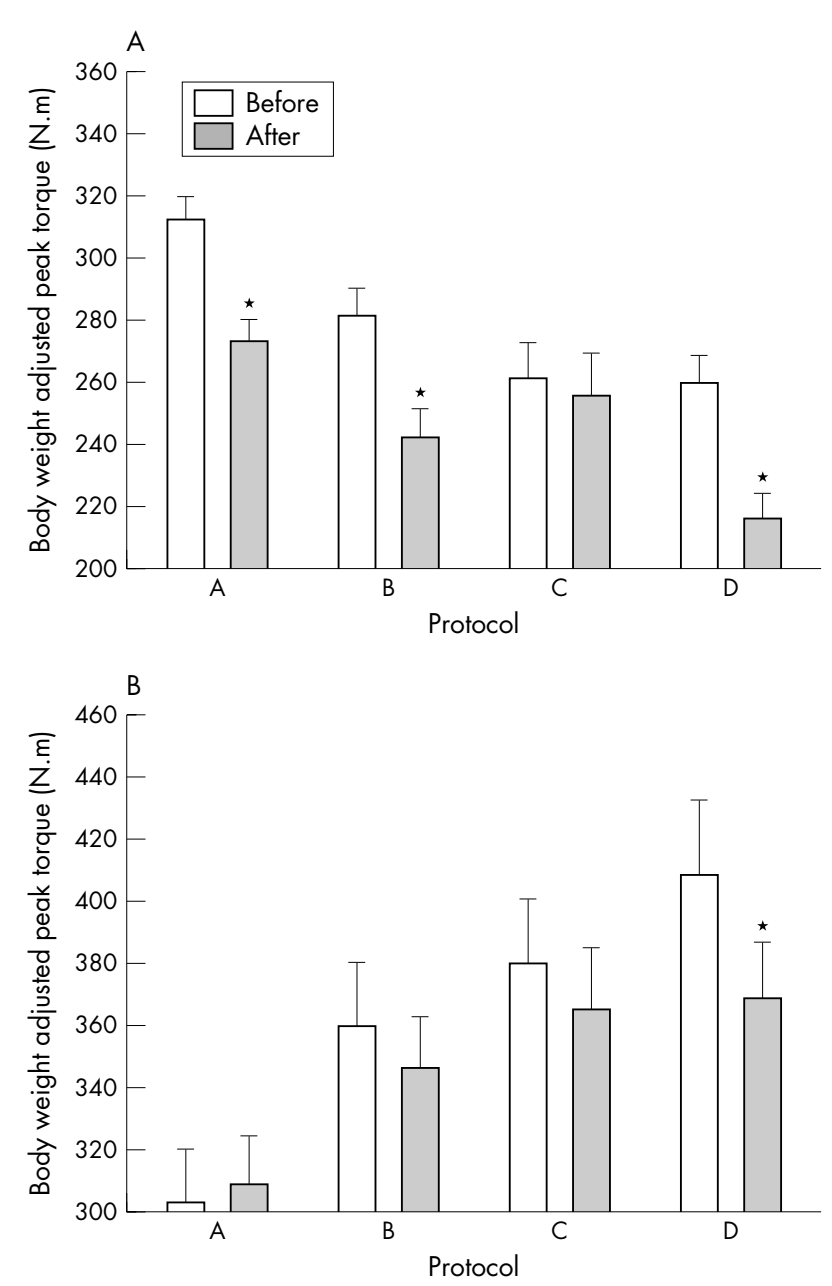

Figure 2 Peak torque values (body weight adjusted) before and after fatigue from all four protocols for flexion (A) and extension (B). Values are mean (SEM). " $p<0.05$ compared with before fatigue.

\section{Protocol A}

Maximum strength before fatigue was measured for both flexion and extension during an isokinetic trunk flexionextension test. This was performed at $60 \%$ and incorporated one trial followed by the test. A five second rest was used to enable the subject to prepare for the fatigue section. A series of 10 maximal isokinetic flexion-extension tests performed at $60 \%$ was then used to fatigue the subject. Again, another five second rest was implemented to enable preparation for testing after fatigue. Strength after fatigue was recorded in the same way as before.

\section{Protocol B}

Maximum strength before fatigue was measured for both flexion and extension during an isokinetic trunk flexionextension test. This was performed at $60 \% \mathrm{~s}$ and incorporated one trial followed by the test. A five second rest was used to

\begin{tabular}{|c|c|c|c|}
\hline Protocol & Before & Fatigue & After \\
\hline $\begin{array}{l}A \\
B \\
C \\
D\end{array}$ & $\begin{array}{l}\text { IK } \times 2 \text { reps } \\
\text { IK } \times 2 \text { reps } \\
\text { IM } 5 \text { s hold } \\
\text { IM } 5 \text { s hold }\end{array}$ & $\begin{array}{l}\text { IK } \times 10 \text { reps } \\
\text { IM } 45 \text { s hold } \\
\text { IK } \times 10 \text { reps } \\
\text { IM } 45 \text { s hold }\end{array}$ & $\begin{array}{l}\text { IK } \times 2 \text { reps } \\
\text { IK } \times 2 \text { reps } \\
\text { IM } 5 \text { s hold } \\
\text { IM } 5 \text { s hold }\end{array}$ \\
\hline
\end{tabular}


enable the subject to prepare for the fatigue section. A 45 second maximal isometric hold at $10^{\circ}$ flexion was then used to fatigue the subject. Again, another five second rest was implemented to enable preparation for testing after fatigue. Strength after fatigue was recorded in the same way as before. The above was then repeated with the fatiguing isometric hold in $10^{\circ}$ extension.

\section{Protocol C}

Maximum strength before fatigue was measured during a five second isometric hold in $10^{\circ}$ flexion. This incorporated one trial followed by the test. A five second rest was used to enable the subject to prepare for the fatigue section. A series of 10 maximal isokinetic flexion-extension tests performed at $60 \%$ was then used to fatigue the subject. Again, another five second rest was implemented to enable preparation for testing after fatigue. Strength after fatigue was recorded in the same way as before. The test was then repeated with the isometric holds in $10^{\circ}$ extension.

\section{Protocol D}

Maximum strength before fatigue was measured during a five second isometric hold in $10^{\circ}$ flexion. This incorporated one trial followed by the test. A five second rest was used to enable the subject to prepare for the fatigue section. A 45 second maximal isometric hold, held at $10^{\circ}$ of flexion was then used to fatigue the subject. Again, another five second rest was implemented to enable preparation for testing after fatigue. Strength after fatigue was recorded in the same way as before. This was then repeated for extension, with the spine being held in $10^{\circ}$ extension. Table 1 gives a summary of the protocols.
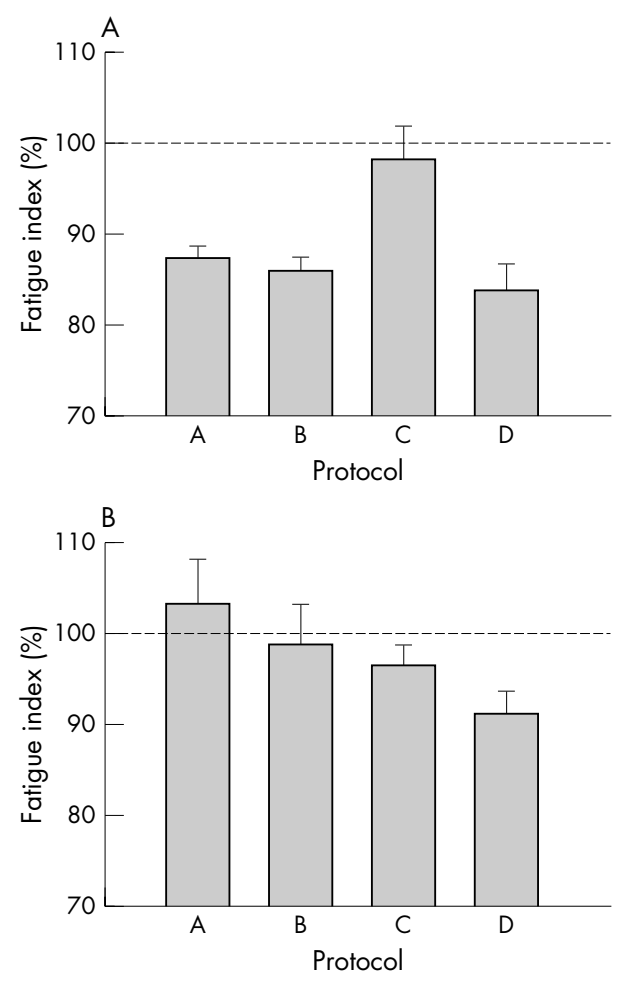

Figure 3 Fatigue index (mean percentage change (value after fatigue/ value before fatigue $\times 100)$ ) in flexion (A) and extension (B). The dashed horizontal line represents the normalised value before fatigue. Values are mean (SEM).

\section{Data analysis}

Body weight adjusted peak torque was used in the final data analyses. This was calculated as a percentage (peak torque $(\mathrm{N} . \mathrm{m})$ divided by body weight $(\mathrm{kg}) \times 100)$. In an attempt to provide a measure of fatigue in terms of change in force output, a fatigue index was determined to quantify the change in data after fatigue. It was calculated as a percentage (value after fatigue divided by value before fatigue $\times 100$ ). Thus if $100 \%$ or more is achieved, no fatigue has occurred, whereas values lower than 100 suggest that fatigue has occurred, the lower the value the greater the fatigue.

Data obtained before and after fatigue in each protocol were examined for differences using the paired Student's $t$ test. In addition, to investigate if a learning effect was evident within the same type of exercise for both flexion and extension, repeated measures analysis of variance was used. All four measures of peak torque under the same conditions were compared-that is, before and after values for isokinetics in protocols A and B, and before and after values for isometrics in protocols C and D. Results were considered significant when $\mathrm{p}<0.05$.

\section{RESULTS}

All 16 subjects completed all four protocols over a four week period. Figure 2 shows the body weight adjusted mean (SEM) peak torque before and after fatigue in flexion and extension. Induction of fatigue appeared to be greater in flexion than extension. The protocols that produced a significant difference in values after fatigue were A, B, and $\mathrm{D}$ in flexion; only protocol D produced significant fatigue in extension. The fatigue index for protocol $\mathrm{A}$ in extension was $103.4 \%$, indicating that the mean peak torque after fatigue was greater than before. Indeed, a larger proportion of subjects (9 of the 16) had an increased measurement for peak torque after the fatiguing section of the protocol than those who had a decreased measurement (fatigued), suggesting a lack of compliance or understanding of the test protocol.

Figure 3 shows the mean percentage change (fatigue index) for each protocol in flexion and extension. Flexion protocols A, B, and D produced similar levels of fatigue, with protocol D producing the greatest fatigue: the mean peak torque after fatigue was $16.2 \%$ less than before, suggesting greatest sensitivity. Protocol C was the least effective at producing fatigue in flexion. Protocol D clearly produced the greatest fatigue in extension $(8.8 \%)$.

With regard to a possible learning effect of the tasks over the four weeks, repeated measures analysis of variance revealed that there were differential effects depending on the type of task. The isokinetic value before fatigue for protocol B (week 3) was significantly $(\mathrm{p}<0.05)$ higher than that for protocol A (week 1) only in extension. For flexion, the isokinetic value before fatigue for protocol B (week 3) was significantly $(\mathrm{p}<0.05)$ lower than that for protocol A (week 1). For the isometric data, there were no differences between the peak values before fatigue at week 1 or 3 in either flexion or extension. These results suggest that learning was not a factor in this study.

\section{DISCUSSION}

Muscle fatigue is an important area of research and performance assessment, and consequently it has been the focus of many studies. ${ }^{462425}$ It is a basic element of muscular performance that potentially has great relevance to activities of daily living, particularly in the trunk, where it is of importance for activities such as bending and lifting. ${ }^{3}$ Fatigue may also have an important role in athletic performance. ${ }^{26}$ However, the optimal method for assessing fatigue has not been clearly established. In fact, Mayer et $a l^{3}$ have suggested that in the back "the measurement of trunk muscle 
What is already known on this topic

- Fatigue has been highlighted to be of importance in the development of low back pain

- In many studies on fatigue a clear definition has not been provided, and often tools used to measure fatigue have not been assessed or validated

endurance remains a more elusive goal than strength measurement".

One of the few validated measures of trunk fatigue is the Biering-Sorenson test, ${ }^{8}{ }^{27}$ which is an isometric test of back extensor strength. However, its principle limitation in fatigue assessment is the fact that it is not a true measure of maximum voluntary contraction, with some suggesting that it records less than $50 \%$ of true maximum contraction ${ }^{3}$ and many questioning the reliability of the measures. ${ }^{328}$ There has also been criticism of this test, as it does not eliminate hip extensor activity. ${ }^{29}$ Also it is limited to the trunk extensors, and attempts to measure flexors with a view to recording fatigue ratios between the two muscle groups have been confounded by the use of submaximal tests performed either against or with the assistance of gravity. ${ }^{30}$

Other studies of trunk fatigue have examined the electromyographic activity of the back muscles using a protocol whereby an exercise, either the holding of an unsupported position such as in the Biering-Sorenson test ${ }^{8}$ or a series of timed flexion-extension movements, is performed until failure. ${ }^{31-33}$ However, there is little consensus on how many or what types of muscle tests are appropriate for inducing this failure. Arguments, however, exist as to what the electromyographic shifts observed are measuring, ${ }^{34}$ and inconsistencies have been noted between subjects with back pain and controls, the relevance of which is unclear as yet. ${ }^{32}$

The ability to study dynamic strength has existed for several years, with protocols primarily consisting of repeated contractions at $50 \%$ of maximal contraction until the point of fatigue. However, owing to the size and role of the trunk muscles, such methods were considered inappropriate by Mayer et $a l^{3}$ because they generated an unacceptably high anaerobic load. Thus, in that study, the subjects performed tests at maximal ability for fewer repetitions, and this was noted to be as reliable as isometric testing in a Roman Chair device. ${ }^{35}$ However, most studies have focused on isometric contractions.

Isometric tests of trunk fatigue and endurance have included chest raises, ${ }^{36}{ }^{37}$ pulling tasks, ${ }^{38}$ and tests performed on sitting ${ }^{39-41}$ or standing dynamometers. ${ }^{23} 42$ During such tests, test position-that is, sitting or standing-has also been noted to affect the results, with Koumantakis et al ${ }^{43}$ suggesting that fatigue testing was more reliable in the upright position. Assessment of the impact of test position, however, was beyond the scope of this study.

Unfortunately, few studies have examined fatigue or endurance of the abdominal muscles, and few have compared isokinetic tasks with isometric tasks, although literature reviews tend to favour the use of isometric testing because of its low cost and equipment demands. ${ }^{29}$ Udermann et $a l^{44}$ examined the repeatability of endurance testing on a Roman Chair device and on a lumbar extension dynamometer, with endurance measured as time to maintain a set level of contraction or to hold a set position. Tests on the dynamometer included both static and dynamic tests, but the results of these different types of test were not compared, as in this study. However, their findings did suggest that all three methods had similar levels of repeatability. The
What this study adds

- This initial study attempts to follow a published definition of fatigue, namely an "exercise induced reduction in maximal voluntary muscle force"

- On the basis of this definition we have investigated different methods for generating and quantifying fatigue, in an attempt to provide a valid fatigue testing protocol

emphasis of their study, however, was on endurance as opposed to fatigue and did not ascertain validity.

Our study was able to compare two different test protocols: isometric and isokinetic. Greater validity was shown in isometric testing. This can be seen in flexion, where protocol $\mathrm{D}$ produced the greatest percentage change in mean peak torque $(16.2 \%)$. It was also the only method to induce significant fatigue in extension $(8.8 \%)$. The finding that fatigue is more readily inducible in the abdominal muscle group than the back extensor muscle group is not new and corroborates findings of Smidt et al. ${ }^{45}$

There are several limitations to this work, the major one being the lack of randomisation of test procedures. However, closer inspection of the data does not show a learning effect. The other limitation is the limited test approaches as it may be that isokinetic testing is appropriate, but an insufficient number of repetitions were performed. This therefore warrants further investigation. Another potential area of concern is the ability of the isokinetic system to isolate muscle groups. It is acknowledged that such systems are unable to totally isolate muscle groups. Therefore further work may be required to investigate the contribution of the hip flexor and extensor groups, although during testing all attempts were made to minimise their activity.

The optimal method of measuring before and after fatigue is not clear. In flexion it can be seen that protocol A (isokinetic testing and fatigue) produces significant fatigue, but when the same isokinetic fatigue period was tested with isometric holds (protocol C), a significant level of fatigue was not produced. This may be the result of increased strength due to training in the previous protocols, ${ }^{1}$ but the timing of testing makes it unlikely that it is due to a learning curve in equipment use. This suggests that isokinetic testing is better at quantifying fatigue.

In extension, the opposite was true; protocol D (isometric testing and fatigue) produced the greatest fatigue, but when the same isometric fatigue period was tested isokinetically (protocol B), it failed to produce a significant level of fatigue. This suggests that isokinetic testing is inferior to isometric testing for determining fatigue. The reasons for this are unclear, although it could be postulated that a five second isometric hold is a more efficient way of achieving peak torque than a single isokinetic flexion and extension movement. Isometric testing was further proved to be superior in extension, revealing greater percentage change for the same fatiguing period when compared with isokinetic results. Isokinetic measurements also appeared less consistent: mean values before fatigue for protocols $\mathrm{A}$ and $\mathrm{B}$ (which should be similar) were significantly different $(p<0.05)$ in both flexion and extension, whereas isometric mean measurements before fatigue were comparable in protocols C and D, especially in flexion where the values were 261.3 and 260.0 N.m respectively. It may be that a five second isometric hold is a more efficient way of achieving peak torque than a single isokinetic flexion and extension movement. Therefore isometric testing can be deemed more appropriate for testing 
fatigue than isokinetic methods. However, further work is needed to examine the repeatability of this test protocol.

During the study, on questioning, subjects perceived higher levels of exertion during protocols involving an isometric fatigue (B and D). It is therefore not surprising that these induced greater levels of fatigue. However, greater levels of perceived exertion do not necessarily correlate with greater levels of fatigue, ${ }^{24}$ although in this study there is support for this concept. A further important implicating factor is motivation, as all forms of endurance of fatigue testing depend on the motivation of the subject to complete the test to his or her own perceived limits of fatigue. ${ }^{29}$ We were unable to quantify or control for this factor, but we did attempt to minimise it by recruiting highly motivated and competitive athletes from the college rugby team.

Overall, the most effective method of inducing and measuring fatigue in the muscles of the trunk was protocol $\mathrm{D}$-that is, isometric testing and fatigue. With mounting evidence that lack of trunk muscle endurance rather that actual strength is a predictor of low back pain, and that fatigue is potentially a key factor that may alter the loads on the spine and impose injury, it is important that a valid and repeatable method of testing fatigue is used in future research studies.

\section{ACKNOWLEDGEMENTS}

We thank the members of Imperial Medics RFC for their participation in this study and the ARC who funded the equipment for this study.

\section{Authors' affiliations}

\section{G Corin, P H Strutton, A H McGregor, Imperial College London, UK}

Competing interests: none declared

Written consent from the subject has been obtained for publication of figure 1 in print and online.

\section{REFERENCES}

1 Gandevia SC. Spinal and supraspinal factors in human muscle fatigue. Physiol Rev 2001;81:1725-89.

2 Bigland-Ritchie B, Woods JJ. Changes in muscle contractile properties and neural control during human muscular fatigue. Muscle Nerve 1984;7:691-9.

3 Mayer T, Gatchel R, Betancur J, et al. Trunk muscle endurance measurement Isometric contrasted to isokinetic testing in normal subjects. Spine, 199515 , 20:920-6.

4 Seghers J, Spaepen A. Muscle fatigue of the elbow flexor muscles during two intermittent exercise protocols with equal mean muscle loading. Clin Biomech (Bristol, Avon) 2004; 19:24-30.

5 Bystrom S, Fransson-Hall C. Acceptability of intermittent handgrip contractions based on physiological response. Hum Factors 1994;36:158-71.

6 Adam A, De Luca CJ. Recruitment order of motor units in human vastus lateralis muscle is maintained during fatiguing contractions. I Neurophysiol 2003:90:2919-27.

7 Chan K, Maffulli N, Norkia P, et al. Principles and practice of isokinetics in sports medicine and rehabilitation. Baltimore: Williams \& Wilkins, 1996.

8 Biering-Sorenson F. Physical measurements as risk indicators for low back trouble over a one-year period. Spine 1984;9:106-19.

9 Brumagne S, Cordo P, Lysens R, et al. The role of paraspinal muscle spindles in lumbosacral position sense in individuals with and without low back pain. Spine, 2000 15, 25:989-94.

10 Fidler MW, Jowett RL, Troup JD. Myosin ATPase activity in multifidus muscle from cases of lumbar spinal derangement. J Bone Joint Surg $[\mathrm{Br}]$ 1975;57:220-7.

11 Hides JA, Stokes MJ, Saide M, et al. Evidence of lumbar multifidus muscle wasting ipsilateral to symptoms in patients with acute/subacute low back pain Spine 1994;19:165-72.

12 Hodges PW, Richardson CA. Inefficient muscular stabilization of the lumbar spine associated with low back pain. A motor control evaluation of transversus abdominis. Spine 1996;21:2640-50.

13 Jowett RL, Fidler MW, Troup JD. Histochemical changes in the multifidus in mechanical derangements of the spine. Orthop Clin North Am 1975;6:145-61.

14 Luoto S, Taimela S, Hurri $\mathrm{H}$, et al. Psychomotor speed and postural control in chronic low back pain patients. A controlled follow-up study. Spine 1996;21:2621-7.
15 Roy SH, De Luca CJ, Casavant DA. Lumbar muscle fatigue and chronic lower back pain. Spine 1989; 14:992-1001.

16 Zhu XZ, Parnianpour M, Nordin M, et al. Histochemistry and morphology of erector spinae muscle in lumbar disc herniation. Spine 1989;14:391-7.

17 Hupli M, Hurri $\mathrm{H}$, Luoto $\mathrm{S}$, et al. Isokinetic performance capacity of trunk muscles. Part I. The effect of repetition on measurement of isokinetic performance capacity of trunk muscles among healthy controls and two different groups of low-back pain patients. Scand J Rehabil Med 1996;28:201-6.

18 Lee JH, Ooi Y, Nakamura K. Measurement of muscle strength of the trunk and the lower extremities in subjects with history of low back pain. Spine, 1995 15, 20:1994-6.

19 Lee JH, Hoshino Y, Nakamura K, et al. Trunk muscle weakness as a risk factor for low back pain. A 5-year prospective study. Spine 1999;24:54-7.

20 Rissanen A, Kalimo H, Alaranta H. Effect of intensive training on the isokinetic strength and structure of lumbar muscles in patients with chronic low back pain. Spine 1995;20:333-40.

21 Takemasa R, Yamamoto H, Tani T. Trunk muscle strength in and effect of trunk muscle exercises for patients with chronic low back pain. The differences in patients with and without organic lumbar lesions. Spine 1995;20:2522-30.

22 Biering-Sorenson F, Thomsen CE. Risk indicators for low back trouble. Scand J Rehabil Med 1989;21:151-7.

23 McGregor AH, Hill A, Grewar J. Trunk strength patterns in elite rowers. Isokinetics \& exercise science 2005; in press.

24 Gorelick M, Brown JM, Groeller H. Short-duration fatigue alters neuromuscular coordination of trunk musculature: implications for injury. Appl Ergon 2003;34:317-25.

25 Rahnama N, Reilly T, Lees A, et al. Muscle fatigue induced by exercise simulating the work rate of competitive soccer. J Sports Sci 2003;21:933-42.

26 Holt PJ, Bull AM, Cashman PM, et al. Kinematics of spinal motion during prolonged rowing. Int J Sports Med 2003;24:597-602.

27 Ortengren R, Andersson B. Electromyographic studies of trunk muscles with special reference to functional anatomy of the lumbar spine. Spine 1977;2:44-52

28 Keller A, Hellesnes J, Brox Jl. Reliability of the isokinetic trunk extensor test, Biering-Sorensen test, and Astrand bicycle test: assessment of intraclass correlation coefficient and critical difference in patients with chronic low back pain and healthy individuals. Spine 2001;26:771-7.

29 Moreau CE, Green BN, Johnson CD, et al. Isometric back extension endurance tests: a review of the literature. J Manipulative Physiol Ther 2001;24:110-22

30 McGill SM, Childs A, Liebenson C. Endurance times for low back stabilization exercises: clinical targets for testing and training from a normal database. Arch Phys Med Rehabil 1999;80:941-4.

31 Clark BC, Manini TM, Ploutz-Snyder LL. Derecruitment of the lumbar musculature with fatiguing trunk extension exercise. Spine 2003;28:282-7.

$32 \mathrm{Ng} \mathrm{JK}$, Richardson CA, Parnianpour M, et al. Fatigue-related changes in torque output and electromyographic parameters of trunk muscles during isometric axial rotation exertion: an investigation in patients with back pain and in healthy subjects. Spine 2002;27:637-46.

33 Sparto PJ, Parnianpour M, Barria EA, et al. Wavelet analysis of electromyography for back muscle fatigue detection during isokinetic constanttorque exertions. Spine 1999;24:1791-8.

34 Mayer TG, Smith SS, Keeley J, et al. Quantification of lumbar function. Part 2. Sagittal plane trunk strength in chronic low-back pain patients. Spine $1985 ; 10: 765-72$

35 Mayer JM, Udermann BE, Graves JE, et al. Effect of Roman chair exercise training on the development of lumbar extension strength. J Strength Cond Res 2003; 17:356-61

36 Ito T, Shirado O, Suzuki H, et al. Lumbar trunk muscle endurance testing: an inexpensive alternative to a machine for evaluation. Arch Phys Med Rehabil 1996;77:75-9.

37 McIntosh G, Wilson L, Affieck M, et al. Trunk and lower extremity muscle endurance: normative data for adults. Journal of Rehabilitation Outcome Measures 1998;2:20-39.

38 Jorgensen K, Nicolaisen T. Two methods for determining trunk extensor endurance. A comparative study. Eur J Appl Physiol Occup Physiol 1986;55:639-44

39 Bonde-Petersen F, Mork AL, Nielsen E. Local muscle blood flow and sustained contractions of human arm and back muscles. Eur J Appl Physiol Occup Physiol 1975;34:43-50.

40 Parkin S, Nowicky AV, Rutherford OM, et al. Do oarsmen have asymmetries in the strength of their back and leg muscles? J Sports Sci 2001;19:521-6.

41 Van Diien JH, Heiibolm P. Reproducibility of isometric trunk extension torque, trunk extensor endurance. And related electromyographic parameters in the context of their clinical applicability. J Orthop Res 1996;14:139-43.

42 Lee $Y$, Kuo C. Factor structure of trunk performance data for healthy subjects. Clin Biomech (Bristol, Avon) 2000;15:221-7.

43 Koumantakis GA, Arnall F, Cooper RG, et al. Paraspinal muscle EMG fatigue testing with two methods in healthy volunteers. Reliability in the context of clinical applications. Clin Biomech (Bristol, Avon) 2001;16:263-6.

44 Udermann BE, Mayer JM, Graves JE, et al. Quantitative assessment of lumbar paraspinal muscle endurance. J Athl Train 2003;38:259-62.

45 Smidt G, Herring T, Amundsen L, et al. Assessment of abdominal and back extensor function. A quantitative approach and results for chronic low-back patients. Spine 1983;8:211-19. 